\title{
THE NOX SYSTEM IN HOMOGENEOUS AND HETEROGENEOUS NUCLEAR WASTE DE-FG07-99ER14938
}

PI: $\quad$ Dan Meisel, Radiation Laboratory, University of Notre Dame, Notre Dame IN 46556. Tel: (574) 631-5457; Fax (574) 631-3646; email: dani@nd.edu

Co-PIs: John Bentley, Ian Carmichael, Daniel M. Chipman, Gordon Hug, Radiation Laboratory, University of Notre Dame, Notre Dame IN 46556

PI: Donald M. Camaioni, Pacific Northwest National Laboratory, P.O. Box 999, Richland, WA 99352.

Tel: (509) 375-2739

Co-PI: Wendy J. Shaw, Pacific Northwest National Laboratory, P.O. Box 999, Richland, WA 99352.

\section{INTRODUCTION}

This report summarizes advances of the above-mentioned EMSP project during the period July 1, 2001-June 30, 2002. The project focuses on the effects of organic chemicals in stored nuclear waste and their impact on pretreatment and tank closure issues. Managing the tank wastes and site cleanup activities requires understanding of the chemistry of organics in aqueous basic solutions that contain high nitrate and nitrite concentrations under the field of $\gamma$ and $\beta$ irradiation. The goal of this EMSP project is to quantitatively characterize the important chemical processes that are induced by radiolysis of the organic complexants, and their degradation products, during the storage in tanks. Furthermore, concerns that arise from pretreatment and tank closure issues, e.g., Tc speciation, can be rationalized with the mechanistic knowledge provided here. Recognizing that experiments cannot reproduce every conceivable realistic scenario, the project emphasizes computational methodologies. None of the Hanford tanks is currently on a watch list, partially due to the predictive understanding of the tanks' chemistry that was developed by these projects and their predecessor activities. The project is closely coupled to another EMSP project (81883) and exchange of information between the two related studies is frequent.

During the report period we developed a computational approach that can describe the fate of organic complexants in HLW. This includes selection of an appropriate computational model, improvement of existing solvation treatments for anions, and development of a theoretical procedure to account for high ionic strength. The model will provide an accurate evaluation of the extent of 
hazardous material, including flammable gases, generation. Experiments to outline pathways and verify computational predictions are also described. Degradation of aminocarboxylate-chelates shows a rich radical-chemistry that results from oxidation by $\mathrm{NO}_{2}, \mathrm{OH}$ and $\mathrm{O}^{-}$radicals. Preliminary results indicate, contrary to prior assumptions, that many radicals react with nitrite, $\mathrm{NO}_{2}^{-}$, by addition (preferentially to the nitrogen) rather than via electron-transfer redox processes.

\section{RESULTS AND DISCUSSION}

Reactions of $\mathrm{NO}_{2}$ radicals: We have shown earlier that $\mathrm{NO}_{2}$ radical is the dominant oxidizing species in typical waste compositions. The interactions of this radical with multifunctional complexants, such as glycolate, and amino-carboxylates were investigated. Initial work focused on simple reactions of $\mathrm{NO}_{2}$. Relative rate constants were measured and reaction products were identified. Electron transfer and $\mathrm{H}$-atom abstraction pathways were identified and the relative importance of a substitution/elimination route was assessed. In highly basic aqueous solution calculations predicted and experiments verified that the oxidizing $\mathrm{NO}_{2}$ is readily converted into $\mathrm{NO}_{3}{ }^{2-}$, a strong reductant. A survey of the expected radicals from the simplest multifunctional complexants was used to calibrate the efficiency and accuracy of the chosen computational procedure using a density functional theory approach. A detailed computational study of the radiolytic oxidation of selected aminocarboxylates in basic aqueous solutions predicted the formation of a number of radical species not reported in earlier experimental work. The calculations also revealed the mechanism for generation of carbon dioxide and the carboxyl radical, $\mathrm{CO}_{2}^{-}$and offered a route to the unusual rearrangement products experimentally observed during long-time radiolysis of waste simulants.

Following earlier observations from $\mathrm{NO}_{2}$ "contact" and radiolysis experiments with waste simulants that contained glycine, we found that glycine degrades to 2-amino-3-hydroxysuccinate (hydroxyaspartate), oxalate, formate and carbonate ions. We also observed that high concentrations of nitrite ion suppress the production of hydroxyaspartate during radiolysis or contact of glycine with $\mathrm{NO}_{2}$. These observations are of concern because they indicate that fuel-rich organics do not necessarily degrade to less energetic and innocuous products. Therefore, we are interested in understanding how hydroxyaspartate forms and why is it suppressed by nitrite ion. Recent work now shows that the hydroxyaspartate forms by aldol condensation of glycine with glyoxylate ion. Glyoxylate is an 
intermediate in the oxidation of glycine and other complexants (HEDTA, EDTA, NTA, glycolate) that were commonly used at Hanford and stored in the tanks. We, and others at Georgia Tech, have shown that glyoxylate converts to $\mathrm{H}_{2}$ and oxalate in highly basic solutions.

$$
\mathrm{H}_{2} \mathrm{NCH}_{2} \mathrm{CO}_{2}^{-} \rightarrow \underset{\text { glyoxylate }}{-\mathrm{O}_{2} \mathrm{CCH}=\mathrm{O}} \rightarrow{ }^{-} \mathrm{O}_{2} \mathrm{CCO}_{2}^{-}+\mathrm{H}_{2}
$$

Our observation of efficient condensation of glyoxylate with glycine under these very same conditions was not known. We have proven it by showing that hydroxyaspartate is generated in good yields when glycine is added to alkaline $(1 \mathrm{M} \mathrm{NaOH})$ solutions of glyoxylate in the absence of radiation or $\mathrm{NO}_{2}$. The following aldol condensation mechanism is proposed:

$$
\begin{aligned}
& \mathrm{H}_{2} \mathrm{NCH}_{2} \mathrm{CO}_{2}{ }^{-}+\mathrm{OH}^{-} \rightarrow \mathrm{H}_{2} \mathrm{NCH}=\mathrm{CO}_{2}{ }^{2-}+\mathrm{H}_{2} \mathrm{O} \\
& \mathrm{H}_{2} \mathrm{NCH}=\mathrm{CO}_{2}{ }^{2-}+{ }^{-} \mathrm{O}_{2} \mathrm{CCH}=\mathrm{O} \rightarrow{ }^{-} \mathrm{O}_{2} \mathrm{C}\left(\mathrm{H}_{2} \mathrm{~N}\right) \mathrm{CHCH}\left(\mathrm{O}^{-}\right) \mathrm{CO}_{2}{ }^{-} \\
& -\mathrm{O}_{2} \mathrm{C}\left(\mathrm{H}_{2} \mathrm{~N}\right) \mathrm{CHCH}\left(\mathrm{O}^{-}\right) \mathrm{CO}_{2}{ }^{-}+\mathrm{H}_{2} \mathrm{O} \rightarrow{ }^{-} \mathrm{O}_{2} \mathrm{C}\left(\mathrm{H}_{2} \mathrm{~N}\right) \mathrm{CHCH}(\mathrm{OH}) \mathrm{CO}_{2}{ }^{-}+\mathrm{OH}^{-}
\end{aligned}
$$

The mechanism for suppression of the condensation reaction by nitrite ions is not clear yet. Possible reactions include addition of $\mathrm{NO}_{2}{ }^{-}$to glyoxylate that slows the rate of the aldol condensation:

$$
{ }^{-} \mathrm{O}_{2} \mathrm{CCH}=\mathrm{O}+\mathrm{NO}_{2}^{-} \rightarrow{ }^{-} \mathrm{O}_{2} \mathrm{CCH}(\mathrm{ONO}) \mathrm{O}^{-}\left(+\mathrm{OH}^{-}\right) \rightarrow{ }^{-} \mathrm{O}_{2} \mathrm{CCO}_{2}{ }^{-}+\mathrm{NO}^{-}+\mathrm{H}_{2} \mathrm{O}
$$

Alternatively, nitrite ion may oxidize glycine radicals directly to oxalate without forming glyoxylate, as in the following:

$\mathrm{H}_{2} \mathrm{NCHCO}_{2}^{-}+\mathrm{NO}_{2}^{-} \rightarrow \mathrm{H}_{2} \mathrm{NCH}\left(\mathrm{NO}_{2}^{-}\right) \mathrm{CO}_{2}^{-} \rightarrow \mathrm{H}_{2} \mathrm{NCH}\left(\mathrm{NO}_{2}^{-}\right) \mathrm{CO}_{2}^{-}(+\mathrm{NO}) \rightarrow \rightarrow^{-} \mathrm{O}_{2} \mathrm{CCO}_{2}^{-}+$ $\mathrm{N}_{2} \mathrm{O}+\mathrm{NH}_{2}$

Both pathways require addition to nitrite, a theme that increasingly becomes evident in its reactions.

Reactions of $\bar{O}$ radicals: At the high $\mathrm{pH}$ of nuclear-waste solutions, radiolysis of water leads to the formation of $\mathrm{O}^{-}$radicals, rather than $\mathrm{OH}\left(\mathrm{p} K_{\mathrm{a}}=11.8\right.$ in dilute solution, but see below). The $\mathrm{O}^{-}$radical- 
ion, in turn, reacts with the organic complexants and their radiolysis fragmentation products. Analogous reactions of $\mathrm{OH}$ with the anionic forms of these aminocarboxylic acids were studied earlier and were found to be close to diffusion controlled. The rates and pathways of these reactions with $\mathrm{O}^{-}$have not been well characterized, but indications are that they are also rapid. Both $\mathrm{OH}$ and $\mathrm{O}^{-}$are strong oxidizing radicals, but are generally acknowledged to react differently because of the charge on the basic form. The latter also responds differently to the high ionic strength.

Fate of the organic radicals: We use time-resolved electron spin resonance (TRESR) detection to identify and to follow the evolution of radicals formed in these radiolytic reactions. Monitoring radicals from the radiolysis of the model chelator, 2-aminobutyrate anions, $\mathrm{H}_{2} \mathrm{~N}-\mathrm{CH}\left(\mathrm{C}_{2} \mathrm{H}_{5}\right) \mathrm{CO}_{2}{ }^{-}$, we detected identical TRESR spectra at $\mathrm{pH} 10$ (from $\mathrm{OH}$ ) and $\mathrm{pH} 13.5$ (from $\mathrm{O}$ ). Thus, both radicals produce the same set of transients from aminobutyrate in spite of their characteristically different modes of oxidative attack. Ethyl radicals, $\mathrm{CH}_{2} \mathrm{CH}_{3}$, which were directly observed, and $\mathrm{CO}_{2}{ }^{-}$radicals, which were identified by spin-trapping, are formed by $\beta$-scission of the initially produced $\mathrm{N}$-centered aminyl radical:

$$
\mathrm{NH}-\mathrm{CH}\left(\mathrm{C}_{2} \mathrm{H}_{5}\right)-\mathrm{CO}_{2}^{-} \rightarrow \mathrm{CH}_{2} \mathrm{CH}_{3}+\mathrm{HN}=\mathrm{CH}-\mathrm{CO}_{2}^{-}
$$

Formally, the initial reaction of $\mathrm{O}^{-}$(and $\mathrm{OH}$ ) is an Hatom abstraction reaction from the amino center of the substrate, $\mathrm{H}_{2} \mathrm{~N}-\mathrm{CH}\left(\mathrm{C}_{2} \mathrm{H}_{5}\right)-\mathrm{CO}_{2}^{-}$. An analogous mechanism may lead to the scission of an (amino) acid residue from chelators, EDTA for example.

Formal electron transfer also occurs and was observed in the oxidation of $\mathrm{H}_{2} \mathrm{~N}-\mathrm{C}\left(\mathrm{CH}_{3}\right)_{2}-\mathrm{CO}_{2}{ }^{-}$to give the transient zwitterionic radical $\left.\mathrm{H}_{2} \mathrm{~N}^{+}-\mathrm{C}_{(} \mathrm{CH}_{3}\right)_{2}{ }_{2} \mathrm{CO}_{2}^{-}$. The latter decarboxylates to give $\mathrm{H}_{2} \mathrm{~N}$ $\mathrm{C}\left(\mathrm{CH}_{3}\right)_{2}$ radicals. A possible pathway for further evolution of complexant fragmentation is through reactions of organic radicals with high nitrite concentrations in nuclear-waste tanks, e.g.:

$$
\mathrm{H}_{2} \mathrm{~N}-\mathrm{C}\left(\mathrm{CH}_{3}\right)_{2}+\mathrm{NO}_{2}^{-} \rightarrow \text { Products }
$$


We have measured the rate constant, $\mathrm{k}=7 \times 10^{7} \mathrm{M}^{-1} \mathrm{~s}^{-1}$ using the TRESR technique. Although the value is smaller than diffusion controlled, this reaction can be a significant evolutionary pathway for organic radicals because of the high nitrite concentrations in the tanks. We suspect that the product is addition to the nitrite. Several other reactions of reactive radicals with $\mathrm{NO}_{2}^{-}$that are presently under investigation show esr spectra of the addition products and will be discussed in later reports.

Solvation Models: Chemical interactions in the Hanford waste tanks are influenced by the presence of high electrolyte concentrations, typically ranging from 1-5 M. In particular, $\mathrm{p} K_{\mathrm{a}}$ values and redox potentials may be substantially affected by the ionic atmosphere. Uncertainty in the $\mathrm{p} K_{\mathrm{a}}$ governing the $\mathrm{OH} / \mathrm{O}^{-}$equilibrium at high ionic strength in $\mathrm{HLW}$ is a major obstacle to quantifying the reactions of primary radiolytic species with $\mathrm{NO}_{2}{ }^{-}$. To help resolve these questions, we are developing a capability to incorporate high ionic strength effects into the reaction field theory of solvation. Our approach utilizes a new and efficient iterative boundary element method adapted for accurate solution of the full nonlinear Poisson-Boltzmann equation. The method is now being implemented and tested in a general computer program for electronic structure calculations of chemical properties in solution.

We use solvation models based on a continuum dielectric representation of the solvent with the solute molecule inside a molecule-shaped cavity embedded in the continuum (in collaboration with $\mathrm{M}$. Dupuis of PNNL). In these models, the interaction of the solute with the solvent is simulated by means of effective charges induced by the solute electron density at the cavity boundary. Important results of benchmark comparisons of experiment and theory have been the finding that anions are not treated well by most standard dielectric continuum models. A powerful semi-empirical protocol that allows computational results to be directly equated with experimental measurements and correlation of cavity shape with quantum mechanical descriptors was developed. Several approaches were tested to determine the shape of the embedded molecule. We finally focus on the interlocking spheres approach. Table 1 lists hydration energies for common species in the waste solutions: $\mathrm{O}_{3}{ }^{-}, \mathrm{NO}_{2}{ }^{-}, \mathrm{HCO}_{2}{ }^{-}, \mathrm{NO}_{3}{ }^{-}$and $\mathrm{ClO}_{2}{ }^{-}$ along with the radii, which reproduce well the experimental values. The radii for the central atom are well predicted by two parameters, the atomic charge $\mathrm{Q}_{\mathrm{x}}$ and the $\mathrm{X}-\mathrm{O}$ bond distance, $\mathrm{D}_{\mathrm{X}-\mathrm{O}}$. We anticipate that our approach can be extended to anions outside the training set, eventually to systems for which solvation data are lacking. 
Table 1:Gibbs Free Energies of Hydration, Cavity Radii, Bond distance and Atomic charges.

\begin{tabular}{|l|c|c|c|c|c|}
\hline Species & $\begin{array}{c}-\mathbf{P G}_{\mathrm{s}}^{*} \\
\mathrm{kcal} / \mathrm{mol}\end{array}$ & $\begin{array}{c}\mathbf{R}_{\mathbf{O}} \\
\AA\end{array}$ & $\begin{array}{c}\mathbf{D}_{\mathbf{X}-\mathbf{O}} \\
\AA\end{array}$ & $\begin{array}{c}\mathbf{R}_{\mathbf{X}} \\
\AA\end{array}$ & $\begin{array}{c}\mathbf{Q X} \\
\text { CHELPG } \\
\text { charges }\end{array}$ \\
\hline $\mathrm{O}^{-}$ & 100 & 1.46 & & & \\
\hline $\mathrm{O}_{2}{ }^{-}$ & 82 & 1.56 & & & \\
\hline $\mathrm{O}_{3}^{-}$ & 70 & 1.59 & 1.352 & 2.12 & 0.076 \\
\hline $\mathrm{NO}_{2}{ }^{-}$ & 69 & 1.6 & 1.264 & 2.04 & -0.087 \\
\hline $\mathrm{HCO}_{2}{ }^{-}$ & 75 & 1.47 & 1.252 & 2.19 & 0.860 \\
\hline $\mathrm{NO}_{3}{ }^{-}$ & 65 & 1.53 & 1.260 & 2.42 & 1.180 \\
\hline $\mathrm{ClO}_{2}{ }^{-}$ & 64 & 1.53 & 1.634 & 2.71 & 0.432 \\
\hline
\end{tabular}

\section{FUTURE DIRECTIONS}

The quantitative contribution of the various species (i.e., $\mathrm{OH} / \mathrm{O}^{-}$and $\mathrm{NO}_{2} / \mathrm{NO}_{3}{ }^{2-}$ ) at the high ionic strength of the waste awaits the development and verification of new theoretical approaches. Similarly, the role of electron-transfer vs. radical-addition reactions of the reactive radicals is now under investigation. These processes may transform an oxidizing (i.e., decreasing fuel content of the waste) to a reducing environment (i.e., fuel generating). Addition of $\mathrm{O}^{-}$to $\mathrm{NO}_{2}^{-}$has already been communicated and recent results show that $\mathrm{H}$ atoms as well as carbon-centered organic radicals also add to nitrite. This is significant as it opens new routes for the generation of organic products via $\mathrm{N}-\mathrm{H}$ and $\mathrm{N}-\mathrm{C}$ bond formation. The rate and yield of these reactions will be quantified and free energies of reactions as well as activation energies for these addition processes will be computed. $\mathrm{NO}_{2}$ contact experiments will examine the nitrilotriacetic acid and iminodiacetic acid systems in simulated alkaline waste solutions to determine their reactivity with $\mathrm{NO}_{2}$ and assess their potential to undergo condensation reactions. The reason for nitrite suppression of glycine- glyoxylate condensation will be elucidated. 